\title{
APLICAÇÃO DE SABUGO DE MILHO COMO SUPORTE PARA IMOBILIZAÇÃO DE LIPASE
}

\author{
D. M COSTA ${ }^{1}$, R. S. S. CASTRO ${ }^{1}$, R. Y. C. PADILHA ${ }^{1}$, D. S. RUZENE ${ }^{2}$, D. P. SILVA ${ }^{2}$, A. \\ S. LIMA ${ }^{1}$ e C. M. F SOARES ${ }^{1}$
}

${ }^{1}$ Universidade Tiradentes, Instituto de Tecnologia e Pesquisa - ITP, Aracaju-SE, Brasil

2 Universidade Federal de Sergipe, Centro de Ciências Exatas e Tecnologia, São Cristovão-SE, Brasil.

E-mail para contato: diego.dmc@gmail.com

\begin{abstract}
A busca por suportes alternativos para imobilização tem motivado diversos estudos na área de enzimologia, deste modo, o uso de sabugo de milho como suporte orgânico, pode ser uma alternativa. Portanto, neste trabalho se verificou a utilização de sabugo de milho como suporte para a imobilização de lipase. A granulometria média do sabugo de milho utilizada foi de 32-60 mesh, e apresentou 27\% celulose, $24 \%$ hemicelulose e $36 \%$ de lignina. Testes de biodegradabilidade do suporte foram realizados, e o suporte não apresentou nenhuma formação de compostos de degradação. A lipase imobilizada apresentou um rendimento de imobilização de $62 \%$ e boa estabilidade operacional, mantendo entre 55 a $60 \%$ da sua atividade inicial até o sexto ciclo. $\mathrm{O} \mathrm{pH}$ e temperatura ótimos para os biocatalisadores imobilizados foram 7,0 e $55^{\circ} \mathrm{C}$. Os parâmetros cinéticos para o modelo de Michaelis-Mentem ( $\mathrm{K}_{\mathrm{m}}$ e $\mathrm{V}_{\max }$ ) foram 616,95 U/g e 361,38, respectivamente.
\end{abstract}

Palavras-chave: Resíduos agroindustriais, materiais lignocelulósicos, sabugo de milho, imobilização, lipase.

\section{INTRODUÇÃO}

O uso de enzimas, especialmente as lipases, está crescendo rapidamente pelo fato destas enzimas apresentarem condições reacionais brandas e poderem ser usadas para diferentes reações (GOTOR-FERNANDEZ et al., 2006). Entretanto, a aplicação de enzimas na sua forma livre é frequentemente dificultada pela desnaturação e inativação e, além disto, não é possível ser facilmente recuperada e reutilizada durante o processo industrial.

Desta maneira, a necessidade de suportes alternativos e mais baratos para imobilização tem motivado estudos de imobilização de enzimas em resíduos agroindustriais, visando aumentar dos produtos obtidos a partir de uma reação enzimática (BRIGIDA et al., 2008). 
Dentre as técnicas de imobilização, a adsorção física é usualmente utilizada, sendo que neste processo estão envolvidas forças de van der Waals, interações hidrofóbicas, pontes de hidrogênio e ligações iônicas fortes. A desvantagem deste processo é a perda de enzima (dessorção) durante o processo de lavagem após a imobilização, como também no processo de reciclagem (CRISTÓVÃO et al., 2011).

Atualmente, materiais lignocelulósicos ganharam importância como suporte para imobilização de enzimas e células, tendo em conta a sua disponibilidade econômica como subprodutos agro-industriais. (CASTRO et al., 2001; DEY et al., 2002; D'SOUZA \& GODBOLE, 2002). Na maioria das vezes, muitos materiais utilizados para imobilização são sintéticos e não biodegradáveis, gerando consequências para o meio ambiente após sua utilização (MOHMOUD, 2007).

Os resíduos agroindustriais utilizados para imobilização de enzimas descritos na literatura atualmente são: como milho, coco, bagaço de cana e palha de arroz. Estes suportes podem ser uma alternativa interessante uma vez que existe em abundância no Brasil como rejeito das indústrias de álcool, açúcares e até mesmo de pequenos produtores (BRIGIDA et al., 2008; CARDOSO et al., 2009; CRISTÓVÃO et al., 2011; SILVA et al., 2012). Assim, o objetivo deste trabalho foi verificar a utilização de sabugo de milho para a imobilização da lipase de Burkholderia cepacia e avaliar a caracterização bioquímica do biocatalisador imobilizado por adsorção física.

\section{MATERIAIS E MÉTODOS}

\subsection{Matéria-prima e Enzima}

Os sabugos de milho usados como matéria-prima neste trabalho foram obtidos do milho híbrido Dow 433, plantado no estado de Sergipe. Os sabugos foram moídos e selecionados de acordo com o tamanho. Em seguida foram submetidos a um processo de lavagem com água destilada, para que fosse retirada todas as impurezas existente no material (seja ela do campo ou do equipamento utilizado para a trituração do material). Como agente enzimático, foi utilizada a Lipase de Burkholderia cepacia - LPS (30.000 U/g), comercializadas pela Amano (Amano Europe Enzyme Ltda., UK).

\subsection{Caracterização química do suporte}

\section{Hidrólise ácida}

Amostras de 2,0 g de sabugo de milho moído e classificado em 32-60 mesh foram tratadas com $10 \mathrm{~mL}$ de $\mathrm{H}_{2} \mathrm{SO}_{4} 72 \%$ (v/v) a $45^{\circ} \mathrm{C}$ por 7 min (ASTM, 1956). Para a completa hidrólise dos oligômeros restantes, os frascos foram autoclavados à $121^{\circ} \mathrm{C}$ por $30 \mathrm{~min}$. Após a descompressão do autoclave, os frascos foram retirados e resfriados à temperatura ambiente, sendo a mistura reacional filtrada e completada com água destilada até um volume de $500 \mathrm{~mL}$. A solução resultante foi utilizada para análises posteriores de lignina solúvel e carboidratos. 


\section{Determinação de lignina}

A lignina insolúvel (lignina Klason), a qual ficou retida no papel de filtro, foi lavada com aproximadamente $1,8 \mathrm{~L}$ de água destilada e seca em estufa a $110^{\circ} \mathrm{C}$ até a observação de massa constante. A lignina solúvel, presente no meio ácido, foi determinada conforme metodologia descrita por Rocha et al. (1997). A medida da absorbância a $280 \mathrm{~nm}$ foi determinada em espectrofotômetro UV/Visível. A linha base foi medida com uma solução contendo $\mathrm{NaOH} 6,5$ $\mathrm{mol} / \mathrm{L}$ sem a adição do hidrolisado.

\section{Determinação de Carboidratos e Ácidos Orgânicos}

O hidrolisado ácido foi extraído em cartuchos de extração sólida Sep-Pak C18 (Waters), para a remoção de compostos aromáticos e, então, injetado diretamente em uma coluna Aminex HPX-87H em um cromatógrafo líquido de alta eficiência (CLAE). Como fase móvel foi empregado $\mathrm{H}_{2} \mathrm{SO}_{4} 0,005 \mathrm{~mol} / \mathrm{L}$ com fluxo de $0,6 \mathrm{~mL} / \mathrm{min}$, a $45^{\circ} \mathrm{C}$. Os compostos foram monitorados com um detector de índice de refração (ROCHA, 1997).

\section{Determinação de Hidroximetilfurfural e Furfural}

Hidroximetilfurfural e furfural foram determinados por CLAE, em uma coluna LiChrospher 100 RP-18 (Hewlett-Packard), utilizando-se acetonitrila/água 1:8 (v/v) com 1\% de ácido acético como fase móvel, a uma vazão de $0,8 \mathrm{~mL} / \mathrm{min}$ a $25^{\circ} \mathrm{C}$. Os compostos foram detectados a $276 \mathrm{~nm}$ (UV/visível Shimadzu SPD-10A), e as respectivas concentrações de hidroximetilfurfural e furfural foram determinadas a partir de curvas de calibração com compostos puros (ROCHA et al., 1997).

\subsection{Imobilização enzimática por adsorção física da lipase}

\section{$\underline{\text { Teste de biodegradabilidade do suporte }}$}

Afim de verificar a estabilidade do suporte na presença da enzima, os testes foram realizados conforme descrito por CABRERA-PADILLA et al. (2013).

\section{Determinação do Carregamento de Enzima}

A determinação da capacidade de adsorção de enzima ao suporte foi obtida analisando a atividade residual alcançada em diferentes relações $(0,15 ; 0,3 ; 0,45$ e 0,6$)$, conforme descrito por CABRERA-PADILLA et al. (2013).

\section{Imobilização por Adsorção Física}

Cerca de $1 \mathrm{~g}$ de suporte foram adicionados a $10 \mathrm{~mL}$ de hexano sob agitação vigorosa em temperatura ambiente durante 2 horas. Em seguida, a solução enzimática contento $0,45 \mathrm{~g}$ de LBC em $10 \mathrm{~mL}$ de solução tampão foram adicionados ao suporte e mantido as condições de agitação por mais 2 horas. Após este período, a solução contendo o sistema imobilizado foi mantendo sem agitação por 24 horas a $4^{\circ} \mathrm{C}$. Posteriormente, a lipase imobilizada foi recuperada por filtração à vácuo e lavado por três vezes, sendo as duas primeiras lavagens com $10 \mathrm{~mL}$ hexano e a terceira com $15 \mathrm{~mL}$. Os filtrados e o biocatalisador imobilizado foram analisados quanto à atividade enzimática 


\section{$\underline{\text { Atividade Lipolítica }}$}

A Atividade foi determinada pelo método de hidrólise do azeite de oliva de acordo com o procedimento descrito por SOARES et al. (1999), com algumas modificações. As análises foram realizadas em triplicata e uma unidade (U) de lipase foi definida como a quantidade de enzima que liberou $1 \mu \mathrm{mol}$ de ácido graxo por minuto de reação, nas condições do ensaio.

\subsection{Caracterização bioquímica do biocatalisador livre e imobilizado}

\section{Influência do $\mathrm{pH}$ e da temperatura}

$\mathrm{O}$ efeito do $\mathrm{pH}$ na atividades da enzimas livre e imobilizada em sabugo de milho foram analisadas numa faixa de $\mathrm{pH}$ entre 4,0 e 9,0 e o efeito da temperatura foi avaliado medindo a atividade em tampão fosfato $\mathrm{pH} 7$ nas temperaturas de 30 a $80^{\circ} \mathrm{C}$.

\section{Determinação dos parâmetros cinéticos}

As velocidades iniciais das reações de hidrólise foram determinadas empregando substratos contendo proporções entre 1 a $60 \%(\mathrm{~m} / \mathrm{v})$ de azeite de oliva em solução aquosa de goma arábica $(7,0 \% \mathrm{~m} / \mathrm{v})$. As velocidades iniciais das reações de hidrólise catalisadas pelas lipases imobilizadas foram determinadas de acordo com a metodologia descrita por SOARES et al. (1999). Os valores de $\mathrm{K}_{\mathrm{m}} \mathrm{e} \mathrm{V}_{\max }$ aparentes foram calculados mediante ajuste não linear com o auxílio do programa Origin ${ }^{\circledR} 8,0$.

\section{$\underline{\text { Estabilidade operacional }}$}

A estabilidade operacional das lipases imobilizadas foi determinada em reações de hidrólise em bateladas consecutivas com reutilização do sistema imobilizado. Neste estudo empregou-se, em todas as bateladas, a mesma massa de biocatalisador imobilizado $(0,1 \mathrm{~g})$. Foram realizadas bateladas de $10 \mathrm{~min}$ cada uma, à temperatura de $50^{\circ} \mathrm{C}$ e $\mathrm{pH} 7,0$.

\section{RESULTADOS}

O sabugo de milho moído apresentou cerca de $10,5 \%$ do resíduo na granulometria de 32 60 mesh. Essa granulometria foi utilizada por ser a mais usualmente descrita na literatura como a de melhor rendimento de imobilização para uso de resíduos agroindustriais (BRIGIDA et al., 2011; CRISTOVÃO et al., 2011). Posteriormente, as amostras de sabugo de milho triturado foram analisadas quanto aos teores de lignina (solúvel e insolúvel), celulose e hemicelulose, bem como de compostos resultantes da degradação no decorrer das análises, como hidroximetilfurfural e furfural, conforme dados apresentadas na Tabela 1.

Tabela 1 - Composição química (\%, m/v) do sabugo de milho.

\begin{tabular}{|c|c|c|c|c|c|}
\hline Celulose & Hidroximetilfurfural & Hemiceluloses & Furfural & \multicolumn{2}{|c|}{ Lignina } \\
\hline $27,4 \pm 0,8$ & $0,21 \pm 0,05$ & $24,3 \pm 1,4$ & $1,2 \pm 0,3$ & $11,2 \pm 1,6$ & $24,5 \pm 2,1$ \\
\hline
\end{tabular}


Os valor da concentração de hemiceluloses, celulose e lignina apresentados na Tabela 1 , provenientes da caracterização para o sabugo de milho, estão de acordo com a literatura (IBRAHIM et al., 2010). A aplicação da hidrólise ácida no sabugo de milho é apontada na literatura como um método eficiente para se obter a degradação da fração lignocelulósica do material. Entretanto, durante o processo químico é comum ocorrer a formação de compostos provenientes da degradação de hexoses e pentoses. Deste modo, é possível observar que o índice de furfural encontrado no decorrer da caracterização do sabugo de milho foi de aproximadamente $1,2 \%$, enquanto para os teores de hidroximetilfurfural foram encontrados $0,21 \%$. Os teores máximos desejados destes componentes é de $1 \%$ (TAMANINI \& HAULY, 2004).

Entre os principais requisitos para um bom suporte é sua capacidade de resistência a degradação por parte do biocatalisador imobilizado, Deste modo, os testes de biodegradabilidade que foram realizados com o sabugo de milho como suporte frente a lipase não apresentaram nenhum tipo de formação de compostos de degradação. Após a avaliação da biodegradabilidade, verificou-se o carregamento de lipase sobre o suporte e se verificou o máximo de rendimento de imobilização foi de $62 \%$.

A determinação do carregamento foi analisada variando a relação enzima/suporte e verificando a atividade relativa apresentada no sistema, conforme mostra a Figura 1. É possível observar que o aumento da carga da enzima possibilitou o aumento na atividade relativa, seguindo este comportamento até um valor de 0,45 de enzima/suporte. Após este valor, ocorreu uma redução na atividade hidrolítica do biocatalisador obtido provavelmente devido a saturação do suporte. Deste modo, a relação de 0,45 entre a enzima e o suporte foi indicado como sendo o valor máximo de carga de enzima suportável na imobilização. As condições experimentais para determinação de carga máxima da enzima imobilizada também foi relatada na literatura por CABRERA-PADILLA et al. (2013), entretanto pode-se verificar que o tipo de lipase e de suporte influencia na quantidade de biocatalisadores imobilizados, pois para o PHBV foi de $0,3 \mathrm{~g}$ de enzima lipase de cândida rugosa por grama de suporte.

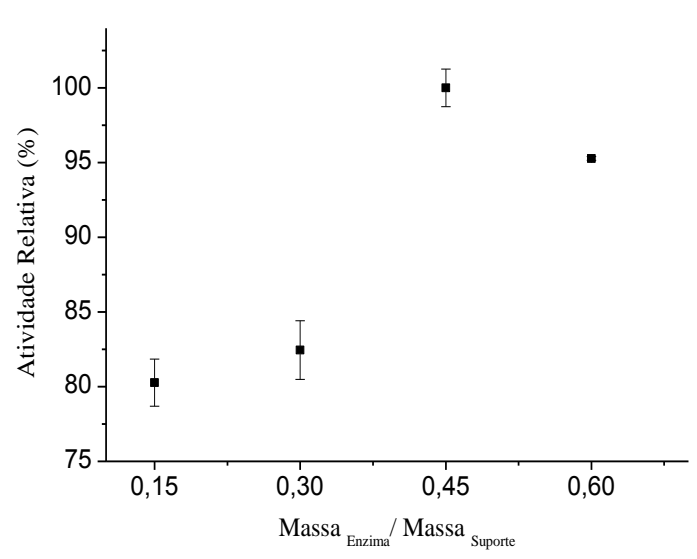

Figura 1 - Relação entre enzima/suporte $(\mathrm{m} / \mathrm{m})$ em função da atividade relativa após a imobilização em sabugo de milho in natura. 
$\mathrm{O}$ perfil da atividade relativa em função do $\mathrm{pH}$ (figura 2a) indicaram que a Lipase de Burkholderia cepacia livre ou imobilizada, apresentaram o pH ótimo 7. Resultados similares foram apresentados por BRIGIDA et al (2007), que analisou a influência do pH na imobilização da Lipase B de candida antarctica em fibra de coco verde.
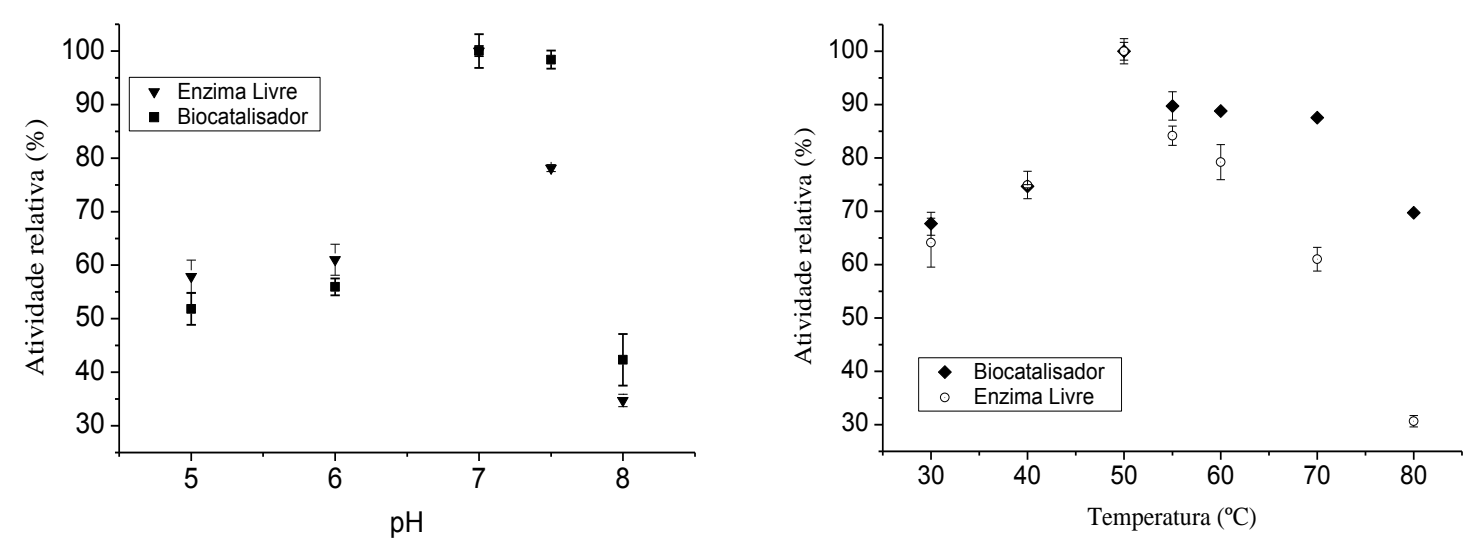

Figura 2 - (a) Efeito do pH na atividade relativa para enzima livre e os biocatalisador imobilizado e (b) Efeito da temperatura na atividade relativa da enzima livre e do biocatalisador imobilizado.

A influência da temperatura na atividade relativa foi verificada com o aumento da temperatura entre os valores de 30 a $50^{\circ} \mathrm{C}$. A Figura $2 \mathrm{~b}$ mostra que a temperatura ótima foi de $50^{\circ} \mathrm{C}$ para o biocatalisador livre e imobilizado, apresentando uma redução na sua atividade para temperaturas superiores.

A determinação dos parâmetros cinéticos do biocatalisador livre e imobilizado foi determinado a partir da conversão de ácidos graxos obtidos na metodologia da atividade hidrolítica. A variação dos valores de $\mathrm{K}_{\mathrm{m}}$ e $\mathrm{V}_{\max }$ relaciona a interação do sítio catalítico da enzima com o suporte sistema imobizado. Os Parâmetros cinéticos $K_{m}$ e $V_{\max }$ foram respectivamente 3246,75 e 227,96 para a biocatalisador livre, e 616,95 e 361,38 para biocatalisador imobilizada em sabugo de milho. Durante o processo de imobilização a enzima pode ser imobilizada de forma a bloquear o acesso ao sítio ativo, reduzindo a afinidade da enzima pelo substrato (aumento do valor de $\mathrm{K}_{\mathrm{m}}$ ) como também pode ocorrer o oposto, mantendo a enzima com a sua conformação aberta que promove um aumento da velocidade máxima $\left(\mathrm{V}_{\max }\right)$ da enzima (FERNANDEZ-LORENTE et al., 2007).

A estabilidade operacional foi verificada a partir da capacidade de reutilização do biocatalisador testado, isto é, estabilidade operacional foi avaliada de acordo com o número de reuso, ou seja, frente a vários ciclos de reação e analisando o teor de ácidos graxos liberados durante esta reação. O biocatalisador imobilizado manteve-se acima de $50 \%$ da sua atividade inicial até o sexto ciclo (Figura 3). 


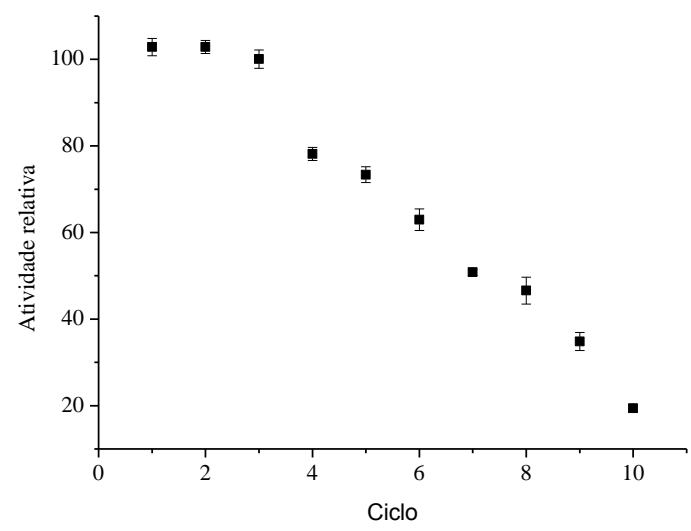

Figura 3 - Número de reuso (ciclo) do biocatalisador imobilizado em sabugo de milho in natura (Sup.00) em função da atividade relativa (\%).

O biocatalisador ainda apresentada cerca de $20 \%$ de sua atividade no $10^{\circ}$ ciclo, sendo sua total inatividade foi alcançada no décimo quarto ciclo.

\section{CONLUSÕES}

O uso do sabugo de milho de milho apresenta um potencial promissor quanto a sua resistência a biodegradação a lipase selecionada. O carregamento de lipase no método de imobilização por adsorção física foi de $0,45 \mathrm{~g} / \mathrm{g}$. Quanto a caracterização bioquímica verificouse os mesmos valores de $\mathrm{pH}$ ótimo $(7,0)$, temperatura ótima $\left(50^{\circ} \mathrm{C}\right)$ e os parâmetros cinéticos indicaram a afinidade do biocatalisador imobilizado ao substrato. A eficiência catalítica e a estabilidade operacional indicam a necessidade de mais estudos quanto a sua otimização.

\section{AGRADECIMENTOS}

Ao PNPD e a Capes pelo suporte financeiro.

\section{REFERÊNCIAS}

ASTM. Methods Standard Test Methods for lignin in Wood. P. 271-48, 1956.

BRIGIDA A.I.S., CALADO V.M.A., GONCALVES L.R.B., COELHO M.A.Z. Effect of chemical treatments on properties of green coconut fiber. Carbohydrate Polymers, vol. 79, p. 832-838, 2011.

BRÍGIDA, A. I. S.; PINHEIRO, A. D. T.; FERREIRA, A. L. O.; GONÇALVES, L. R. B. Immobilization of Candida Antarctica lipase B by adsorption to green coconut fiber. Applied Biochemistry and Biotechnology, v.146, p.173-187, 2008.

BRÍGIDA, A.I.S.; PINHEIRO, A.D.T.; FERREIRA, A.L.O.; GONÇALVES, L.R.B. Immobilization of Candida antarctica lipase B by covalente attachment to green coconut fiber. Applied Biochemistry and Biotecnology, vol. 136, p. 67-80, 2007.

CABRAL, J.M.S.; BARROS, M.R.A.; GAMA, M. Engenharia Enzimática. Lisboa: Lidel, 2003.

CABRERA-PADILLA, R.Y.; ALBUQUERQUE, M.; FIGUEIREDO, R.T.; FRICKS, A.T.; FRANCESCHI, E.; LIMA, A.S.; A DOS SANTOS, O.A.; SILVA, D.P.; SOARES, C.M. 
Immobilization and characterisation of a lipase from a new source, Bacillus sp. ITP-001. Bioprocess Biosyst. Eng., v. 35, p. 1385-1394, 2013.

CARDOSO, C.; MORAES, M. C.; CASS, Q. B. Imobilização de enzimas em suportes cromatográficos: uma ferramenta na busca por substâncias bioativas. Química Nova, vol.32, p. 175-187, 2009.

CASTRO, H. F.; LIMA, R.; ROBERTO, I. C. Rice straw as a support for immobilization of microbial lipase. Biotechnology Progress, v.17, p.1061-1064, 2001.

CRISTÓVÃO, R. O.; TAVARES, A. P.M.; BRÍGIDA, A. I.; LOUREIRO, J. M.; BOAVENTURA, R. A.R.; MACEDO, E. A.; COELHO, M. A. Z. Immobilization of commercial laccase onto green coconut fiber by adsorption and its application for reactivetextiledyesdegradation. Journal of Molecular Catalysis B: Enzymatic, Vol. 72, p. 6-12, 2011.

CRUZ, J. M.; DOMÍNGUEZ, J. M.; DOMÍNGUEZ, H.; PARAJÓ, J. C. Preparation of fermentation media from agricultural wastes and their bioconversion to xylitol. Food biotechnology, v.14, p.79-97, 2000.

D’SOUZA, S. F.; GODBOLE, S. S. Immobilization of invertase on rice husk using olyethylenimine. J. of Bioch. and Biophysical Methods, v.52, p.59-62, 2002.

DEY, G.; NAQPAL, V.; BANERJEE, R. Immobilization of alpha-amylase from Bacillus circulans GRS 313 on coconut fiber. Appl Biochem Biotechnol., p.303-313, 2002.

FENGEL, D.; WEGENER, G. Wood chemistry, ultrastruture, reactions. Berlin: Walter de Gruyter, 1989.

FERNANDEZ-LORENTE, PALOMO, J.M.; CABRERA, Z.; FERNANDEZ-LAFUENTE, R.; GUISAN, J.M. Improved catalytic properties of immobilized lipases by the presence of very low concentrations of detergents in the reaction medium. Biotechnology and Bioengineering, v. 97, p. 242-250, 2007.

GOTOR-FERNANDEZ, V., BRIEVA, R., GOTOR, V., Lipases: Useful biocatalysts for the preparation of pharmaceuticals. J. Mol. Catal B-Enzym., v. 40, p.111-120. 2006.

IBRAHIM, M.M., AGBLEVOR, F.A., EL-ZAWAWY, W. K. Isolation and characterization of celulose and lignina from stem-exploded lignocellulosic biomass. BioResources, vol. 5, p. 397-418, 2010.

MOHMOUD, D.A.R. Immobilization of invertase by a new economical method using wood sawdust waste. Journal Australian Basic and Applied, vol. 1, p 364-372, 2007.

RIVAS, B.; MOLDES, A.B.; DOMINGUEZ, J.M.; PARAJÓ, J.C. Lactic acid production from corn cobs by simultaneous saccharification and fermentation: a mathematical interpretation. Enzyme and Microbial Technology, v. 34, p. 627-634, 2004.

ROCHA, G.J.M.; SILVA, F.T.; CURVELO, A.A.S.; ARAÚJO, G.T. A fast and accurate method for detemination of cellulose and polyoses by HPLC. In: Brazilian Symposium on Chemistry of Lignins and Other Wood Componens, 5, Curitiba, Brasil, v.6, p.3-8, 1997.

SILVA, A. M.; TAVARES, A. P. M.; ROCHA, C. M. R.; CRISTOVÃO, R. O.; TEIXEIRA, J. A.; MACEDO, E. A. Immobilization of commercial laccase on spent grain. Process Biochemistry, v.47, p.1095-1101, 2012.

SOARES, C. M. F.; CASTRO, H. F.; MORAES, F. F.; ZANIN, G. M. Characterization and utilization of Candida rugosalipase immobilized on controlled pore sílica. Applied Biochemistry and Biotechnology, v. 77, p. 745-757, 1999.

TAMANINI, C.; HAUALY, M. C. O. Resíduos Agro-industrial para produção biotecnológica de xylitol. Semina, v. 25, p. 315-330, 2004. 